\title{
Clinical and radiological outcomes after management of traumatic knee dislocation by open single stage complete reconstruction/repair
}

\author{
Michael T Hirschmann*1, Nadia Zimmermann1,2, Thomas Rychen'1, Christian Candrian³, Damir Hudetz4, \\ Lukas G Lorez ${ }^{1}$, Felix Amsler ${ }^{5}$, Werner Müller ${ }^{1}$ and Niklaus F Friederich ${ }^{1,2}$
}

\begin{abstract}
Background: The purpose of our study was to analyze the clinical and radiological long-term outcomes of surgically treated traumatic knee dislocations and determine prognostic factors for outcome.

Methods: Retrospective consecutive series of patients treated surgically for traumatic knee dislocation with reconstruction/refixation of the anterior ( $A C L$ ) and posterior cruciate ligaments $(P C L)$ and primary complete repair of collaterals and posteromedial and posteromedial corner structures. 68 patients were evaluated clinically (IKDC score, SF36 health survey, Lysholm score, Knee Society score, Tegner score, visual analogue scale - VAS pain and satisfaction, Cooper test) and radiologically (weight bearing and stress radiographs) with a mean follow up of $12 \pm 8$ years. Instrumented anterior-posterior translation was measured (Rolimeter, KT-1000). Pearson correlation and stepwise regression analysis was used.

Results: $82 \%$ of patients $(n=56$ ) returned to their previous work. At final follow-up 6 patients (9\%) suffered from pain VAS > 3. The mean side-to-side difference of anterior/posterior translation (KT-1000, 134N) was $1.6 \pm 1.6 \mathrm{~mm}$ and $2.6 \pm$ $1.4 \mathrm{~mm}$. Valgus and varus stress testing in $30^{\circ}$ flexion was $<3 \mathrm{~mm}$ (normal) in 57 patients (86\%). The IKDC score was normal/nearly normal in 38 (58\%) patients and the mean Lysholm score $83 \pm 17$ (intact $98 \pm 7$ ). The median Tegner score decreased from 7 preinjury (range 3-10) to 5 at follow-up (range 0-10). The mean Knee Society score was $187 \pm$ 15 (out of maximum 200). In 7 patients (10\%) a secondary ligament reconstruction was performed. Three patients (4\%) underwent a high tibial osteotomy and four (6\%) received a primary unconstrained total knee replacement. According to the Kellgren Lawrence osteoarthritis score only mild degenerative changes were present. The stress radiographs showed stable results for anteroposterior translation. Injury of the lateral collateral ligament, refixation of the ACL/PCL and delayed surgery $>40$ days were significantly associated with worse outcome $(p<0.05)$.

Conclusions: Early complete reconstruction can achieve good functional results and patient satisfaction with overall restoration of sports and working capacity. Negative predictive factors for outcome were injury pattern, type of surgical procedure and timing of surgery.
\end{abstract}

\section{Background}

Traumatic dislocation of the tibiofemoral joint is considered to be rare in Europe and western civilized countries[1,2], but when present it often has dramatic social and economic consequences for the patient[3-9]. Spontaneous reduction makes the true frequency of knee dislo-

* Correspondence: Michael.Hirschmann@ksbh.ch

1 Department of Orthopaedic Surgery and Traumatology, Kantonsspital Bruderholz, Bruderholz, CH-4101, Switzerland

Full list of author information is available at the end of the article cation unclear. Radiological imaging, particularly MRI, regularly underestimates the severity of this injury[10,11]. Dislocation inevitably results in a severe ligamentous injury because of the complex anatomy of the knee joint. However, the exact injury pattern is still a matter of controversy. In fact, traumatic knee dislocation typically leads to injuries of both cruciate ligaments[12], but there have been a few reports of patients with a documented knee dislocation and injury to only one cruciate ligament[13-16]. A tear of both cruciate ligaments with 
injury to the medial or lateral corner is considered to be a reliable indicator of sustained but spontaneously reduced traumatic knee dislocation[17].

There are a few, predominantly retrospective studies that include a small number of cases, which often address epidemiology, diagnosis and treatment strategy for traumatic knee dislocations in a heterogenous group of patients[8,9,17-34]. Very little knowledge is available on the clinical and radiological long-term outcomes after treatment of these severe ligament injuries. The question of an optimal treatment concept has not been answered adequately. The purpose of our study was to analyze the clinical and radiological outcomes of traumatic knee dislocations treated surgically between 1980 and 2006 in our institution according to a consistent treatment philosophy and to determine factors that predict a better or worse outcome. Our hypothesis was that good results could be achieved in the majority of patients by the implementation of our standardized surgical approach and postoperative protocol.

\section{Methods}

A review of the medical records in the hospital archives was conducted. This yielded 89 consecutive patients with a sustained knee dislocation who were treated surgically between January 1980 and August 2006. Only patients with a radio- or photographically documented knee dislocation or bicruciate ligament injury and associated injury to at least one collateral ligament were included. Exclusion criteria and patient selection are shown in Figure 1. Ultimately, 74 patients were finally included in the present study. Of these 68 patients had received primary sur-

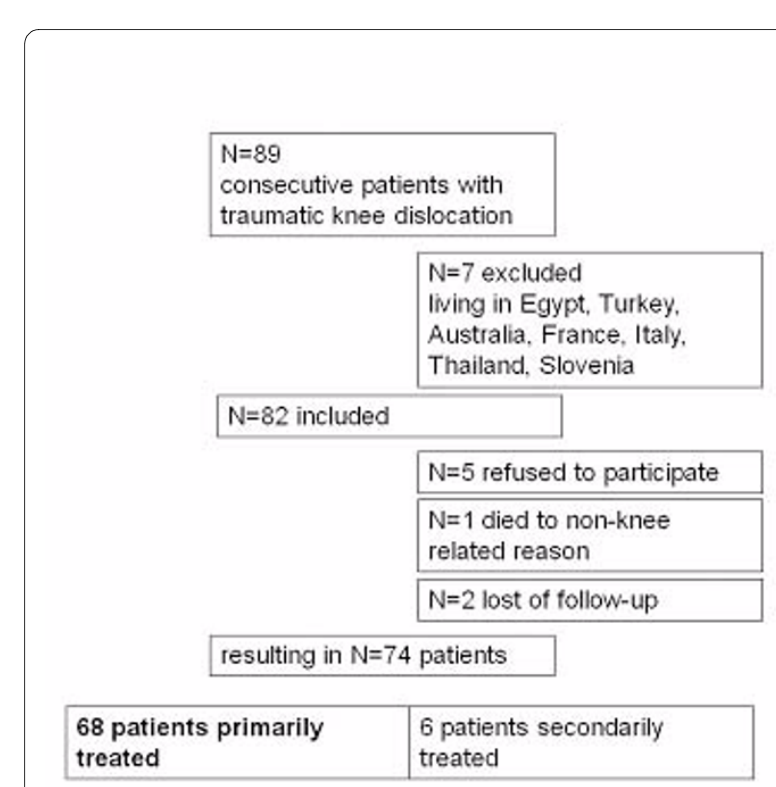

Figure 1 Patient selection. gery and 6 patients secondary surgery (Fig 1.). To homogenize the study population only the results for patients initially treated at our institution were described. Of the patients who received primary surgery 48 were treated within 2 weeks of the trauma and 20 after 2 weeks (within 2-4 weeks $\mathrm{n}=7$, within 4-8 weeks $\mathrm{n}=5$, >8 weeks $\mathrm{n}=8)$. The study was approved by the local ethics committee (EK 307/06).

\section{Surgical technique}

The treatment philosophy advocating early open complete ligament reconstruction of the central pivot and peripheral lesions is based on the recommendations and expertise of one of the senior authors. A major goal of the surgical reconstruction was the best possible anatomical restoration of joint biomechanics, which, in our opinion, can only be achieved by a complete restoration of the primary and secondary knee stabilizers[35]. Whenever possible surgery was performed 10-14 days after the injury when the soft tissue swelling had resolved and range of motion had been regained. However, not every patient presented at our clinic at that point in time.

Initially, diagnostic arthroscopy of the knee was undertaken to evaluate the degree of meniscal, cartilaginous and ligamentous injury. A maximum water pressure of 20 $\mathrm{mmHg}$ was used and the lower leg was continuously monitored for swelling to preclude compartment syndrome. In cases of meniscal lesion, the damaged tissue was either sutured in outside-in technique with PDS sutures (Johnson \& Johnson, Spreitenbach, Switzerland) or partially removed.

Subsequently, a proximal thigh tourniquet was inflated to $300 \mathrm{mmHg}$ and surgery was continued in open technique. A lateral skin incision and a lateral or medial parapatellar arthrotomy, depending on the pattern of the ligamentous injury, was performed. In cases of a midsubstance tear, the anterior and posterior cruciate ligaments were reconstructed and bone avulsions were managed by screw or suture refixation. Reconstruction of the ACL was performed in anatomical single-bundle technique with ipsilateral patellar tendon autograft. The reconstruction of the PCL was performed in single-bundle tibial onlay technique with ipsilateral quadriceps tendon autograft.

The collateral ligaments and posterolateral/posteromedial corner structures were repaired by insertion of at least three resorbable Z-sutures (Vicryl ${ }^{\circ} 2-0$, Ethicon, Germany) fixed to a metal anchor (Mitek, DePuy, Spreitenbach, Switzerland). If necessary, popliteal bypass surgery was performed according to the technique described by Müller[35]. All ligaments were tensioned at the end of surgery in the following order: PCL, ACL and finally the collateral ligaments. Detailed descriptions of the recon- 
struction and refixation techniques have been given previously[35].

Postoperatively the patients were permitted to partial weight bear with an extension splint (3/4 scotch cast splint with $10^{\circ}$ extension deficit) from the first week and continued partial weight bearing for a total of six weeks. Limited passive and active, assisted knee flexion was initiated directly after surgery for six weeks. After six weeks the patients progressed to full active knee flexion. The rationale of this protocol was to protect the reconstruction grafts from mechanical stress and allow sufficient motion to prevent arthrofibrosis.

\section{Follow-up}

The median follow-up time was $12 \pm 8$ years (range 1-27). Demographic data (profession before and after injury, ability to work, need for workers compensation, time to return to work) was noted. Patients were examined by one senior orthopaedic resident who had not been involved in the index surgery.

For clinical outcome assessment we used the International Knee Documentation Committee (IKDC2000) Standard Evaluation Form (demographic, subjective and functional evaluation form)[36-38], the SF36 health survey[39], the Lysholm score[40], the Tegner score[40] and the Knee Society score[41]. The examination included assessment of ACL and PCL laxity with the KT-1000 arthrometer (Medmetric, San Diego, U.S.A.) in $25^{\circ}$ flexion with $67 \mathrm{~N}, 89 \mathrm{~N}$ and $134 \mathrm{~N}$ and with the Rolimeter (Ormed, Freiburg, Germany) in $25^{\circ}$ and $70^{\circ}$ flexion. Collateral ligament laxity was tested clinically with varus or valgus stress in extension and $30^{\circ}$ flexion. The Cooper asymmetry test (Dial test) was performed in $30^{\circ}$ and $90^{\circ}$ flexion. In addition, we specified the extent of the patient's subjective perceived impairment on a visual analogue scale $(0-10)$ to evaluate pain $(0=$ best value and 10 $=$ poorest value $)$ and satisfaction $(10=$ best value and $0=$ poorest value).

\section{Radiological evaluation}

Weight-bearing radiographs of the injured knee (anteroposterior and lateral views), a tangential view of the patella and a Rosenberg view ( $45^{\circ}$ flexion posterior-anterior weight bearing) were obtained. The mechanical alignment of the leg was assessed on full length weightbearing radiographs. Stress radiographs were obtained with the Telos device (Telos $\mathrm{GmbH}$, Hölstein, Switzerland) in $30^{\circ}$ and $90^{\circ}$ flexion for both knees to determine anterior and posterior translation.

The medial and lateral joint space height was measured on the Rosenberg view and on anteroposterior weightbearing radiographs. Any osteoarthritis of the knee joint was graded according to the Kellgren-Lawrence Osteoarthritis score[42]. This score has a five-level scale (grade 0: normal; grade 1: suspected osteoarthritis; grade 2: minimal osteoarthritis; grade 3: moderate osteoarthritis, and grade 4: severe osteoarthritis). All measurements were made precisely using the PACS (Picture Archiving Communication System, Phillips Easy Vision, Netherlands).

\section{Statistical methods}

Data were analyzed using SPSS 13.0 (SPSS, Chicago, U.S.A.). Continuous variables were described using means, standard deviations and ranges. Categorical variables were tabulated as absolute and relative frequencies. Pearson's correlation was used to compute associations between variables. Multivariate influence on several outcome variables was tested by stepwise regression analysis. Variables were entered in four blocks using $\mathrm{p}<0.1$ as entry criteria and $\mathrm{p}>0.2$ as removal criteria. Missing values were replaced by the mean. Age at injury, time since injury, gender, physical profession and highest level of education were entered in a first block, Tegner score before injury and smoking in a second block, medial injuries, lateral injuries and peroneal nerve injuries in a third block and type of ACL and PCL surgery in a forth block. Significant variables were marked and adjusted $\mathrm{R}$ squares were computed to show the goodness of fit of the multivariate models.

\section{Results}

\section{Patients and interventions}

Patient demographics and injury pattern are shown in Table 1. In 20 patients suture refixation of the anterior cruciate ligament (ACL) and in 48 patients a reconstruction with bone-patellar tendon-bone autograft was performed. In 30 patients (44\%) screw refixation of the posterior cruciate ligament (PCL), in 17 patients (25\%) suture refixation and in 21 patients (31\%) reconstruction with quadriceps tendon autograft was performed. In addition, $6 \%(n=4)$ required partial medial meniscectomy, $4 \%(\mathrm{n}=3$ ) partial lateral meniscectomy, $22 \%(\mathrm{n}=$ 15) suture refixation of the medial meniscus, and $31 \%$ (n $=21)$ of the lateral meniscus. $60 \%(n=41)$ had their superficial and/or deep MCL and 31\% $(\mathrm{n}=21)$ had their LCL repaired. 14 patients (21\%) required a popliteal bypass and in 3 patients (4\%) the biceps tendon was reinserted with a metal anchor in the fibula. The peroneal nerve was reconstructed in two patients. No vascular intervention was necessary.

\section{Clinical outcome}

$82 \%$ of patients $(n=56)$ returned to their previous work. The mean time to return to work was $9 \pm 13$ months. $10 \%$ of patients $(n=7)$ received full workers compensation. At follow-up, 62 patients (91\%) had a VAS pain less than or equal to 3 . The results for the visual analogue scale for pain, satisfaction, the total SF36 score, active and passive 
Table 1: Patient demographics and injury pattern $(n=68)$.

\begin{tabular}{ll}
\hline Mean age at injury (years) & $30 \pm 11$ \\
\hline Time since injury (years) & $12 \pm 8$ \\
\hline Side of injury (right, left) & $\mathrm{n}=32(47 \%), \mathrm{n}=36(53 \%)$ \\
\hline Gender (male, female) & $\mathrm{n}=58(85 \%), \mathrm{n}=10(15 \%)$ \\
\hline Mean height (cm) & $176 \pm 8$ \\
\hline Mean weight (kg) & $79 \pm 11$ \\
\hline $\begin{array}{l}\text { BMI } \\
\text { Insurance status (private, } \\
\text { public) }\end{array}$ & $25 \pm 3$ \\
\hline
\end{tabular}

\begin{tabular}{ll}
\hline Highest level of education & \\
\hline Secondary school graduation & $35(51 \%)$ \\
\hline High school graduation & $2(3 \%)$ \\
\hline Professional training & $16(24 \%)$ \\
\hline University degree & $\mathrm{n}=11(16 \%)$ \\
\hline Post-graduate & $\mathrm{n}=1(1.5 \%)$ \\
\hline Missing & $\mathrm{n}=3(4.5 \%)$ \\
\hline Profession & $\mathrm{n}=34(50 \%) \mathrm{n}=34(50 \%)$ \\
\hline Physical Non-physical
\end{tabular}

\begin{tabular}{ll}
\hline \multicolumn{2}{l}{ Sports activity prior to trauma } \\
\hline None & $\mathrm{n}=11(17 \%)$ \\
\hline only rarely & $\mathrm{n}=33(50 \%)$ \\
\hline regularly & $\mathrm{n}=22(32 \%)$ \\
\hline no comment & $\mathrm{n}=2(3 \%)$ \\
\hline Injury & \\
\hline Sport & $\mathrm{n}=33(49 \%)$ \\
\hline
\end{tabular}

Table 1: Patient demographics and injury pattern $(n=68)$.

\begin{tabular}{|c|c|}
\hline motor vehicle accident & $n=28(41 \%)$ \\
\hline work-related injury & $\mathrm{n}=7(10 \%)$ \\
\hline Smoking & $\mathrm{n}=33(49 \%)$ \\
\hline \multicolumn{2}{|l|}{ Injury pattern } \\
\hline$A C L$ & $\mathrm{n}=68(100 \%)$ \\
\hline$P C L$ & $\mathrm{n}=68(100 \%)$ \\
\hline Superficial MCL & $\mathrm{n}=49(72 \%)$ \\
\hline Deep MCL & $\mathrm{n}=44(65 \%)$ \\
\hline Medial meniscus & $\mathrm{n}=15(22 \%)$ \\
\hline Semimembranosus muscle & $\mathrm{n}=5(7 \%)$ \\
\hline$L C L$ & $n=22(32 \%)$ \\
\hline Popliteus tendon & $\mathrm{n}=21(31 \%)$ \\
\hline Biceps tendon & $\mathrm{n}=8(12 \%)$ \\
\hline Lateral meniscus & $\mathrm{n}=20(29 \%)$ \\
\hline Peroneal nerve & $\mathrm{n}=3(4 \%)$ \\
\hline Popliteal artery (intimal) & $\mathrm{n}=2(3 \%)$ \\
\hline
\end{tabular}

knee flexion and extension, the Lysholm score and the Tegner score are presented in Table 2.

13 patients (19\%) presented with an extension deficit when compared to the uninjured side $\left(5^{\circ} \mathrm{n}=7,7^{\circ} \mathrm{n}=1\right.$, $\left.10^{\circ} \mathrm{n}=5\right)$. Clinically, 13 patients $(19 \%)$ presented with a patella infera compared to the uninjured side. During Lachman's maneuver and anterior drawer testing 64 patients $(99 \%)$ had a firm endpoint. The pivot shift test was normal in $46(72 \%)$, nearly normal in 15 (23\%), and abnormal in 3 patients (5\%).

The mean anterior laxity in $\mathrm{mm}$ measured with the KT1000 arthrometer was $1.5 \pm 1.0(67 \mathrm{~N}), 2.7 \pm 1.5(89 \mathrm{~N})$ and $4.2 \pm 2.5(134 \mathrm{~N})$. The mean posterior laxity in mm measured with the KT-1000 arthrometer was $2.0 \pm 1.1(67 \mathrm{~N})$, $3.2 \pm 2.1(89 \mathrm{~N})$, and $5.4 \pm 2.0(134 \mathrm{~N})$. The mean side-toside difference for anterior and posterior laxity measured with $134 \mathrm{~N}$ was $1.6 \pm 1.6 \mathrm{~mm}$ and $2.6 \pm 1.4 \mathrm{~mm}$. The ante- 
rior translation measured with the rolimeter in $25^{\circ}$ flexion was <3 $\mathrm{mm}$ in 46 (72\%), 3-5 $\mathrm{mm}$ in 17 (26.5\%) and 6$10 \mathrm{~mm}$ in 1 patient (1.5\%). In $70^{\circ}$ flexion it was $<3 \mathrm{~mm}$ in 42 (64\%), 3-5 $\mathrm{mm}$ in 22 (33\%) and 6-10 $\mathrm{mm}$ in 2 patients (3\%). The posterior drawer test with rolimeter in $70^{\circ}$ flexion was $<3 \mathrm{~mm}$ in 44 patients (63\%), 3-5 $\mathrm{mm}$ in 22 patients (31\%), $6-10 \mathrm{~mm}$ in 2 patients (3\%). Valgus stress testing in $30^{\circ}$ flexion was $<3 \mathrm{~mm}$ in 57 patients (86\%), 3-5 $\mathrm{mm}$ in 8 patients (12\%), $6-10 \mathrm{~mm}$ in one patient $(1.5 \%)$. Varus stress testing in $30^{\circ}$ flexion was $<3 \mathrm{~mm}$ in 57 patients (86\%), $3-5 \mathrm{~mm}$ in 8 patients $(12 \%), 6-10 \mathrm{~mm}$ in one patient $(1.5 \%)$. Cooper asymmetry testing at $30^{\circ}$ showed $<6^{\circ}$ (normal) difference in $41,6^{\circ}-10^{\circ}$ (nearly nor$\mathrm{mal}$ ) in $13,11^{\circ}-19^{\circ}$ (abnormal) in 3 , and $>19^{\circ}$ (severely abnormal) in 7 patients. In $90^{\circ}$ flexion the difference was $<6^{\circ}$ in 49 patients, $6^{\circ}-10^{\circ}$ in $8,11^{\circ}-19^{\circ}$ in 4 and $>19^{\circ}$ in 3 patients.

59 patients $(89 \%)$ did not show any donor site morbidity. In 4 patients (6\%) kneeling was tender and in $3(5 \%)$ impossible due to pain. The relative length of a one leg hop in comparison to the uninjured side was $>90 \%$ in 40 (64\%), $76-89 \%$ in 12 (19\%), $50-75 \%$ in $4(6 \%)$ and $<50 \%$ in 7 patients.

The IKDC subscore for range of motion was A (normal) in 27 (40\%), B (nearly normal) in 30 (45\%), C (abnormal) in $9(13 \%)$ and D (severely abnormal) in 1 patient (1.5\%). The IKDC subscore for ligament laxity was A (normal) in 14 (21\%), B (nearly normal) in 30 (46\%), C (abnormal) in $13(20 \%)$, and D (severely abnormal) in 9 patients (13\%). The total IKDC score was A (normal) in 5 (8\%), B (nearly normal) in 33 (50\%), C (abnormal) in 18 (27\%) and D (severely abnormal) in $10(15 \%)$ patients.

\section{Complications and secondary surgeries}

At final follow-up 6 patients (9\%) had a poor result suffering from a pain level VAS $>3$. 4 patients were not able to flex their knee more than $110^{\circ}$. Three of them underwent at least one secondary surgery. Overall, in 32 of 68 patients (47\%) secondary surgeries including screw removals were undertaken during follow-up. In seven (10\%) patients a secondary ligament surgery was performed. Four patients (6\%) received a primary unconstrained total knee replacement during the follow-up period, namely, at 2, 2, 17 and 23 years after injury. In three patients (4\%) a high tibial osteotomy (in one patient medial and lateral) was performed $0.5,1,3$ and 5 years after injury. Detailed data on these patients is given in Additional file 1.

\section{Radiological outcome}

On the full length weight-bearing radiographs 37 (54\%) patients showed a varus, $21(31 \%)$ a valgus and 10 patients $(15 \%)$ a neutral mechanical alignment. The mean medial and lateral joint space height in the Rosenberg view was $2.8 \pm 2.5 \mathrm{~mm}$ and $4.4 \pm 2.1 \mathrm{~mm}$. The mean medial and lateral joint space height in the weight bearing anteroposterior view was $2.9 \pm 2.4 \mathrm{~mm}$ and $4.2 \pm 1.5 \mathrm{~mm}$. The Kellgren Lawrence score was 0 (normal) in none, I in 47 patients (suspected osteoarthritis), II in 10 patients (minimal osteoarthritis), III in 10 patients (moderate osteoarthritis), and IV in 1 patient (severe osteoarthritis).

The results of the anterior/posterior stress radiographs in $30^{\circ}$ and $90^{\circ}$ flexion are shown in Table 3.

\section{Uni- and multivariate correlations}

The results for the univariate correlations are shown in Table 4. Age and time since injury correlate with pre- and postinury Tegner score and the need of secondary surgery. Higher education level correlates with better quality of life, less pain and higher injury correlated scores. Medial side injuries have better outcome than lateral side or peroneal nerve injuries. Reconstruction of ACL correlates with better outcome whether reconstruction of PCL does not correlate with any of the outcomes. Multivariate influence on several of the outcome variables is presented in Table 5. The independent variables explain between $9 \%$ (SF-36) and 47\% (Tegner score) of the different outcome variables. Patient age at injury does not have any influence on outcome, but time since injury correlates significantly with Tegner score and need for secondary surgery. Education is a very strong independent source for better outcome. Medial side injuries have a positive and peorneal nerve injury a negative influence on outcome also in the multivariate regression model whereas type of surgery does not add significant information.

\section{Discussion}

This study, to our knowledge the largest consecutive long-term series on the surgical treatment of traumatic knee dislocations, has produced the following major results.

Firstly, on average 12 years after one-stage open complete reconstruction of traumatic knee dislocations 3/5 of patients showed good to excellent subjective and objective results. On average only $10^{\circ}$ loss of flexion was observed. 4/5 of patients returned to their previous work but, on average, the activity level reflected in the Tegner score relevantly decreased from injury to last follow-up. The IKDC score was normal or nearly normal in 3/5 of patients and the Lysholm and Knee Society score showed good to excellent results. The instrumented anterior and posterior laxity measurements with the KT-1000 arthrometer demonstrated good to excellent results at mean 12 years after injury. Less than $5 \%$ of patients in the present study had an abnormal ( $>6 \mathrm{~mm}$ ) anterior or posterior laxity measured with the rolimeter. These results are consistent with the findings of Tzurbakis et al.[31] who found $1.6 \pm 1.9 \mathrm{~mm}$ and $2.3 \pm 1.7 \mathrm{~mm}$ of anterior and 
Table 2: Subjective and objective outcome at last follow-up.

\begin{tabular}{|c|c|c|}
\hline Outcome parameter & mean \pm SD & median (range) \\
\hline VAS pain & $1.4 \pm 1.6$ & $1(0-6)$ \\
\hline VAS satisfaction & $8.8 \pm 1.4$ & $9(4-10)$ \\
\hline SF36 score & $81 \pm 15$ & $85(47-100)$ \\
\hline SF36 physical & $50 \pm 7$ & $52(21-60)$ \\
\hline SF36 mental & $54 \pm 8$ & $55(32-65)$ \\
\hline Active ipsilateral knee extension & $2^{\circ} \pm 3^{\circ}$ & $0^{\circ}\left(0-10^{\circ}\right)$ \\
\hline Active contralateral knee extension & $3^{\circ} \pm 4^{\circ}$ & $0^{\circ}\left(0-10^{\circ}\right)$ \\
\hline Active ipsilateral knee flexion & $127^{\circ} \pm 9^{\circ}$ & $130^{\circ}\left(100^{\circ}-140^{\circ}\right)$ \\
\hline Active contralateral knee flexion & $135^{\circ} \pm 7^{\circ}$ & $0^{\circ}\left(0^{\circ}-10^{\circ}\right)$ \\
\hline Lysholm score injured side & $83 \pm 17$ & $87(24-100)$ \\
\hline Lysholm score uninjured side & $98 \pm 7$ & $100(55-100)$ \\
\hline Relative Lysholm score & $85 \% \pm 17 \%$ & $90 \%(24 \%-100 \%)$ \\
\hline Tegner score preinjury & $7.0 \pm 1.8$ & $7(3-10)$ \\
\hline Tegner score at follow-up & $4.9 \pm 2.4$ & $5(0-10)$ \\
\hline Knee Society score & $187 \pm 15$ & $191(118-200)$ \\
\hline
\end{tabular}

posterior translation side-to-side difference. Varus und valgus laxity did not appear to be a major problem. It was normal $(<3 \mathrm{~mm})$ in $86 \%$ of our patients. This finding is consistent with those obtained by others[19]. Clearly, the measured values of anterior-posterior and varus-valgus laxity reflect a stable knee status in the majority of our patients, which was one major goal of our reconstructive treatment protocol.

Comparison of results with other studies on the treatment of knee dislocations is difficult as study populations often differ with regards to age, injury pattern, demographics, body mass index and treatment protocol. Most authors agree that non-surgical treatment with cast immobilization produces inferior results compared to surgical treatment regimens $[5,17,29,43]$. A variety of surgical procedures both open[8,21,27,29,31,44] and arthroscopy-assisted $[19,21]$ have been reported.
Using a similar open treatment strategy as ours Tzurbakis et al. reported comparable functional results in terms of instrumented anterior/posterior laxity and Lysholm and Tegner scoring for a series of 25 patients with a follow-up of 2-8 years[31]. Richter et al. reported on a series of patients and compared the outcomes of surgically and non-surgically treated patients. They found inferior results in terms of the IKDC and Lysholm and Tegner scores, which may be explained by the high number of polytraumatized patients in their series[17]. As a referral center for severe knee ligament injuries we often see trauma patients after primary stabilization and care in another hospital, which partly explains the low rate of neurovascular injuries in our series.

With an arthroscopy-assisted combined ACL/PCL reconstruction technique Fanelli et al. reported excellent, mildly superior results with regard to the Lysholm score 
and Tegner activity score, but the follow-up was rather short[19]. Also Harner et al. and Owens et al. found comparable results for the Lysholm score, loss of flexion, and KT 1000 laxity of the ACL and PCL. However, less patients achieved normal or nearly normal on the total IKDC score[20]. Although in recent years there has been a shift toward arthroscopy-assisted techniques, to our knowledge, all these studies have recorded only equivalent or inferior results in terms of subjective and objective outcomes compared to our long-term series. In addition, several injuries such as posterolateral or posteromedial corner injuries, fractures or avulsed tendons cannot or should not be treated arthroscopically. Therefore, we still propose our treatment protocol (including arthrotomy and open surgery) in acute cases of patients with multiple ligament injuries as a valuable treatment option. In our view, the question of which surgical approach the orthopedic surgeon should choose, i.e. open or arthroscopyassisted, is only of marginal importance. It is far more the experience and teamwork of the surgeons, physiotherapists and nurses involved in the treatment that makes the difference.

Secondly, we believe that in this study stress radiographs in $30^{\circ}$ and $90^{\circ}$ flexion obtained with the Telos device have, for the first time, shown convincing longterm laxity results for anterior and posterior translation in surgically treated patients after traumatic knee dislocation. To our knowledge, only Fanelli et al. have to date reported comparable findings with a mean side-to-side difference in posterior translation of $3.2 \mathrm{~mm}$ in posterior stress radiographs[19]. Our instrumented radiographic stress testing in both anterior and posterior directions confirmed the clinical impression of a stable ACL and PCL in our long-term series of patients.

Controversy persists as to whether early surgical repair of the ligaments decreases the incidence of posttraumatic osteoarthritis compared with non-surgical treatment. In the present study only a mild degree of osteoarthritis was evident in most of the patients treated according to the Kellgren Lawrence Osteoarthritis score. Only 11 patients (16\%) showed a Kellgren Lawrence score of grade III or IV, namely moderate or severe osteoarthritis. This was also reflected by our joint space measurements. This is in accordance with Richter et al.[17] who reported mostly mild and moderate osteoarthritic changes after a similar follow-up time. Interestingly, more degenerative changes were found in the non-surgically treated group of patients, which may be attributed to abnormal joint kinematics due to ligamentous instability. In contrast, Almekinders et al. did not find any difference in radiologically visible degenerative changes of the knee joint between surgically and non-surgically treated patients[45].

Thirdly, we had to accept an unavoidable rate of persistent problems, secondary surgeries and reoperations in this heavily injured patient population. Unfortunately, several authors failed to report their rate of secondary surgeries and/or reoperations[21,22,24]. The biggest problem we encountered after reconstructive surgery was continued pain and loss of motion. A pain level VAS $>3$ was found in $9 \%$ of patients. Decreased ability to flex the knee $<110^{\circ}$ was present in 4 patients. Seven patients (10\%) underwent an arthroscopic arthrolysis during follow-up, which is consistent with the literature[20,27,31].

Instability was not really an issue for most of the patients followed-up in our series, which is reflected by the fact that only 7 patients (10\%) underwent a secondary ligament reconstruction during the follow-up period. Three of them were a consequence of insufficient stability after the previous surgery. All but one reoperated patient received ACL suturing and/or PCL refixation. The number of patients requiring high tibial osteotomy or with a primary unconstrained total knee arthroplasty was low considering the long-term follow-up.

Fourthly, according to our results injury pattern, timing of surgery and the chosen surgical treatment might play a crucial role in the long-term prognosis.

In the present study, long-term outcome was significantly influenced by the type of injury.

We found that patients with an injury of the LCL and/ or the peroneal nerve had a higher need for workers compensation ( $p<0.01$ ). Oswald et al.[25] found similar results reporting that patients with an injury on the lateral side had a less favourable outcome than patients with an injury on the medial side.

The timing of surgery significantly influenced patient's need for workers compensation. Generally it depends on the vascular status of the extremity, soft tissue conditions, concomitant injuries, comorbidities and the injury pattern. There is no doubt that an irreducible knee dislocation, dislocations associated with popliteal artery injury, or open dislocations demand emergency surgical management. In all other cases, there is a general consensus

Table 3: Tibial translation $(\mathrm{mm})$ on stress radiographs in $30^{\circ}$ and $90^{\circ}$ flexion in comparison of injured and uninjured side.

\begin{tabular}{|c|c|c|c|c|}
\hline & $30^{\circ}$ anterior & $30^{\circ}$ posterior & $90^{\circ}$ anterior & $90^{\circ}$ posterior \\
\hline & mean \pm sd & mean \pm sd & mean $\pm s d$ & mean $\pm s d$ \\
\hline R/L difference & $2.3 \pm 15.2 \mathrm{~mm}$ & $1.8 \pm 4.0 \mathrm{~mm}$ & $-2.7 \pm 5.7 \mathrm{~mm}$ & $4.5 \pm 5.5 \mathrm{~mm}$ \\
\hline
\end{tabular}


Table 4: Univariate analysis of outcome data.

\begin{tabular}{|c|c|c|c|c|c|c|c|c|c|c|c|c|c|c|c|}
\hline & SF-36 & $\begin{array}{c}\text { SF-36 } \\
\text { physical }\end{array}$ & $\begin{array}{l}\text { SF-36 } \\
\text { mental }\end{array}$ & $\begin{array}{l}\text { VAS } \\
\text { pain }\end{array}$ & $\begin{array}{c}\text { VAS } \\
\text { satis-faction }\end{array}$ & $\begin{array}{c}\text { Knee } \\
\text { Society score }\end{array}$ & $\begin{array}{l}\text { Tegner } \\
\text { preinjury }\end{array}$ & $\begin{array}{l}\text { Tegner } \\
\text { follow up }\end{array}$ & $\begin{array}{l}\text { Tegner } \\
\text { change }\end{array}$ & $\begin{array}{c}\text { Lysholm } \\
\text { uninjured side }\end{array}$ & $\begin{array}{c}\text { Lysholm } \\
\text { injured side }\end{array}$ & $\begin{array}{c}\text { Lysholm } \\
\text { relative }\end{array}$ & $\begin{array}{l}\text { Secon-dary } \\
\text { surgery }\end{array}$ & $\begin{array}{l}\text { Need for workers } \\
\text { com-pensation }\end{array}$ & $\begin{array}{l}\text { Need to change } \\
\text { pro-fession }\end{array}$ \\
\hline Age at follow up & & & & & & & $-0.47^{* * *}$ & $-0.36^{* *}$ & & & & & $0.29^{*}$ & & \\
\hline Age at injury & & & & & & & $-0.41^{* * *}$ & & & & & & & & \\
\hline Time since injury & & & & & & & $-0.25^{*}$ & $-0.42 * * *$ & $-0.33^{* *}$ & $-0.24^{*}$ & & & $0.56^{* * *}$ & & \\
\hline Female sex & & & $0.23^{t}$ & & & & $-0.30^{*}$ & & & & & & & & \\
\hline Physical profession & & & & & & & & & & & & & & & $0.32^{* *}$ \\
\hline Higher education & $0.27^{*}$ & $0.35^{* *}$ & & $-0.32^{* *}$ & $0.35^{* *}$ & $0.28^{*}$ & $0.21^{\mathrm{t}}$ & $0.36^{* *}$ & $0.27^{*}$ & $0.28^{*}$ & $0.30^{*}$ & & $-0.32^{* *}$ & $-0.28^{*}$ & \\
\hline Tegner preinjury & & $0.24^{t}$ & & & & & - & $0.51^{* * *}$ & & & & & $-0.21^{t}$ & & \\
\hline Smoking & $-0.23^{t}$ & & & & & & & $-0.31^{*}$ & $-0.35^{* *}$ & & $-0.34^{* *}$ & $-0.31^{*}$ & & & \\
\hline Medial side injuries & & & & $-0.36^{* *}$ & $0.31^{* *}$ & $0.31^{* *}$ & & & & & & $0.23^{t}$ & & $-0.32^{* *}$ & \\
\hline Lateral side injuries & & & $-0.21 t$ & $0.25^{*}$ & & $-0.23 \mathrm{t}$ & & & & & & & & & \\
\hline $\begin{array}{l}\text { Peroneal nerve } \\
\text { injury }\end{array}$ & $-0.26^{*}$ & & $-0.27^{*}$ & $0.35^{* *}$ & $-0.32^{* *}$ & $-0.29^{*}$ & & & & & & & $0.23^{t}$ & $0.4^{* * *}$ & \\
\hline $\begin{array}{l}\text { Time between injury } \\
\text { and surgery }>40\end{array}$ & & & & & & & & & & & & & & & $0.35^{* *}$ \\
\hline$\overline{\mathrm{ACL}}$ reconstruction & $0.23^{\mathrm{t}}$ & $0.23^{t}$ & & $-0.22^{t}$ & & & & $0.27^{*}$ & $0.27^{*}$ & & $0.24^{t}$ & & $-0.23^{t}$ & $-0.21^{t}$ & $0.21^{\mathrm{t}}$ \\
\hline
\end{tabular}


Table 5: Stepwise regression analysis on several outcome variables: Adjusted R square of the entire model, and significant influence.

\begin{tabular}{|c|c|c|c|c|c|c|c|}
\hline & SF 36 total & VAS pain & VAS satis-faction & Knee Society score & Tegner score $^{\&}$ & Secondary surgery & Need for workers compensation \\
\hline Adjusted R Square & 0.09 & 0.25 & 0.21 & 0.16 & 0.47 & 0.41 & 0.24 \\
\hline \multicolumn{8}{|c|}{ Block 1: Age and gender } \\
\hline \multicolumn{8}{|l|}{ Age at injury } \\
\hline Time since injury & & & & & $-* *$ & $+* * *$ & \\
\hline \multicolumn{8}{|l|}{ Gender } \\
\hline \multicolumn{8}{|c|}{ Block 2: Concomitant aspects } \\
\hline \multicolumn{8}{|l|}{ Physical profession } \\
\hline Education & $+^{t}$ & $-* *$ & $t^{* *}$ & $+^{* *}$ & $+^{*}$ & $-* *$ & $-*$ \\
\hline Tegner preinjury & & & & & $+^{* * *}$ & & \\
\hline Smoking & & & & & $-* *$ & & \\
\hline \multicolumn{8}{|c|}{ Block 3: Number of injuries } \\
\hline Medial side injuries & & $--^{* *}$ & $+^{* *}$ & $+^{* *}$ & $+^{* *}$ & & $-*$ \\
\hline \multicolumn{8}{|l|}{ Lateral side injuries } \\
\hline $\begin{array}{l}\text { Peroneal nerve } \\
\text { injury }\end{array}$ & $-\mathrm{t}$ & $+^{t}$ & & & & $+^{t}$ & $+^{*}$ \\
\hline
\end{tabular}

\section{Block 4: Type of surgery}

$A C L$ reconstruction

PCL reconstruction

\&Time since injury and Tegner preinjury explain $\mathrm{R}^{2}=.34 ; \mathrm{t} p<0.1,{ }^{*} \mathrm{p}<0.05,{ }^{* *} \mathrm{p}<0.01,{ }^{* * *} \mathrm{p}<0.001$

to wait with reconstruction until the inflammatory response has subsided and the full range of motion has been regained. The risk of arthrofibrosis, a major adverse event associated with premature reconstruction, is considered to be less if surgery is postponed until 2-3 weeks after injury[28]. Owens et al. advocated a surgical reconstruction within 2 weeks of the injury and Rihn et al. within 3 weeks of the injury[7,26]. Postponement of surgery beyond 3-4 weeks is not recommended as this may result in excessive scarring of the collateral ligaments[7,28].

The answers to the question of whether a ligamentshould be reconstructed or not vary greatly in the litera- ture. Most authors advocate a one-stage surgical reconstruction of at least both cruciate ligaments $[8,19,20]$. Only a few authors reported the results of a multistage procedure. In 2002, Ohkoshi et al. reported good range of motion and antero-posterior laxity (KT1000 manual maximum) after a two-stage surgical approach (first stage 2 weeks after injury: reconstruction of posterior cruciate ligament, second stage three months later: reconstruction of ligaments that have not healed as a result of non-surgical treatment). However, only eight patients were included in this series[24].

The choice of surgical treatment was significantly associated with better or worse outcome. We found that 
patients who underwent ACL suturing had a less favourable outcome than patients with reconstruction. Our findings are comparable to those obtained by Mariani et al., who found that patients treated by direct repair had less favorable results in terms of laxity and range of motion than reconstructed patients [22]. Wong et al. found that surgical treatment involving the complete repair of all injured structures was superior in terms of IKDC score and antero-posterior laxity when compared to partial repair (unicruciate ligament reconstruction)[33].

The selection of grafts is still based more on surgeon's preference and availability of grafts than evidence[4]. Patellar tendon, quadriceps tendon and hamstring tendons of the ipsi- or contralateral side have been used as autografts for reconstruction in traumatic knee dislocations. Several authors prefer allografts (Achilles tendon, patellar tendon, tibialis anterior tendon, hamstring tendons) as surgical time and donor site morbidity may be decreased in this complex reconstructive setting $[19,23,32]$. To our knowledge there is no study demonstrating the superiority of allografts in terms of clinical outcome and ligament laxity in comparison to autografts in multi-ligament injured knees. In addition, allografts are hardly available in Europe. Synthetic grafts have occasionally been used in reconstructive surgery in patients with traumatic knee dislocations[24,30]. A series of 20 patients was evaluated retrospectively by Talbot et al. with a minimum follow-up of one year, yielding inferior results in terms of the Lysholm score, range of motion and ligament laxity[30].

We are aware that this investigation is subject to all the problems inherent in a retrospective study setting, but investigating patients treated for traumatic knee dislocations is hardly feasible in a prospective way. As there is no control group we compared our results to the available literature. However, our study has an extraordinary follow-up rate and is a consecutive series of patients treated at our hospital over a period of 27 years. In the present study performing multiple univariate analysis of about 200 correlations might have led to false positive results in about $10(\mathrm{p}<0.05)$ or $20(\mathrm{p}<0.1)$ cases and hence the results should be interpreted with all due caution.

\section{Conclusions}

On the basis of our results we advocate early single stage complete reconstruction of both cruciate ligaments and all peripheral structures. Suture refixation of the anterior cruciate ligament should be avoided due to inferior longterm outcomes. Although in recent years there has been a shift toward arthroscopy-assisted techniques, we still propose our treatment protocol (including arthrotomy and open surgery) in acute cases of patients with multiple ligament injuries as a valuable treatment option. In our view, the question of which surgical approach the orthopedic surgeon should choose, i.e. open or arthroscopyassisted, is only of marginal importance. It is far more the experience and teamwork of the surgeons, physiotherapists and nurses involved in the treatment that makes the difference.

\section{Additional material}

Additional file 1 Reoperated patients.

\section{Competing interests}

The authors declare that they have no competing interests.

\section{Authors' contributions}

$\mathrm{MH}$ set up the protocol, organized ethics approval, carried out the study and drafted the manuscript. NZ participated in the design of the study, the radiological follow-up and helped with the analysis of radiological data. TR participated in the design of the study and clinical follow-up. CC participated in the design of the study and clinical follow-up and helped with the draft of the manuscript. DH participated in the clinical follow-up and helped with the draft of the manuscript. LGL participated in the design of the study and clinical follow-up and helped with the draft of the manuscript. FA participated in the design of the study and performed the statistical data analysis. WM participated in the design of the study and helped with the draft of the manuscript. NFF participated in the design of the study, interpretation of results and helped with the draft of the manuscript. All authors read and approved the final manuscript.

\section{Acknowledgements}

The authors thank the Swiss National Insurance Trust (SUVA) for their financial support of this research and the team of MTRA's for obtaining the time-consuming stress radiographs. We also thank Joy Buchanan for native language editing and Kenneth De Haven, MD for reviewing the manuscript.

\section{Author Details}

1Department of Orthopaedic Surgery and Traumatology, Kantonsspital Bruderholz, Bruderholz, CH-4101, Switzerland, 2Faculty of Medicine, University of Basel, Basel, CH-4001, Switzerland, ${ }^{3}$ Department of Surgery Ospedale Civico, Via Tesserete, Lugano, CH-6903, Switzerland, 4Department of Traumatology, University Hospital Zagreb, Croatia and ${ }^{5}$ Amsler Consulting, Biel-Benken, Switzerland

Received: 30 July 2009 Accepted: 27 May 2010

Published: 27 May 2010

\section{References}

1. Twaddle BC, Bidwell TA, Chapman JR: Knee dislocations: where are the lesions? A prospective evaluation of surgical findings in 63 cases. $J$ Orthop Trauma 2003, 17(3):198-202.

2. Brautigan B, Johnson DL: The epidemiology of knee dislocations. Clin Sports Med 2000, 19(3):387-397.

3. Klimkiewicz JJ, Petrie RS, Harner CD: Surgical treatment of combined injury to anterior cruciate ligament, posterior cruciate ligament, and medial structures. Clin Sports Med 2000, 19(3):479-492.

4. Giannoulias CS, Freedman KB: Knee dislocations: management of the multiligament-injured knee. Am J Orthop 2004, 33(11):553-559.

5. Dedmond BT, Almekinders LC: Operative versus nonoperative treatment of knee dislocations: a meta-analysis. Am J Knee Surg 2001, 14(1):33-38

6. Henrichs A: A review of knee dislocations. J Ath/ Train 2004, 39(4):365-369

7. Rihn JA, Groff YJ, Harner CD, Cha PS: The acutely dislocated knee: evaluation and management. J Am Acad Orthop Surg 2004, 12(5):334-346

8. Martinek V, Steinbacher G, Friederich NF, Muller WE: Operative treatment of combined anterior and posterior cruciate ligament injuries in 
complex knee trauma: can the cruciate ligaments be preserved? Am Knee Surg 2000, 13(2):74-82.

9. Hirschmann MT, Iranpour F, Muller W, Friederich NF: Surgical Treatment of Complex Bicruciate Knee Ligament Injuries in Elite Athletes: What Long-term Outcome Can We Expect? Am J Sports Med . DOI: 10.1177/ 0363546509356978

10. Lonner JH, Dupuy DE, Siliski JM: Comparison of magnetic resonance imaging with operative findings in acute traumatic dislocations of the adult knee. J Orthop Trauma 2000, 14(3):183-186.

11. Twaddle BC, Hunter JC, Chapman JR, Simonian PT, Escobedo EM: MRI in acute knee dislocation. A prospective study of clinical, MRI, and surgical findings. J Bone Joint Surg Br 1996, 78(4):573-579.

12. Wascher DC, Dvirnak PC, DeCoster TA: Knee dislocation: initial assessment and implications for treatment. J Orthop Trauma 1997 11(7):525-529.

13. Bellabarba C, Bush-Joseph CA, Bach BR Jr: Knee dislocation without anterior cruciate ligament disruption. A report of three cases. Am J Knee Surg 1996, 9(4):167-170.

14. Cooper DE, Speer KP, Wickiewicz TL, Warren RF: Complete knee dislocation without posterior cruciate ligament disruption. A report of four cases and review of the literature. Clin Orthop Relat Res 1992:228-233.

15. Shelbourne KD, Pritchard J, Rettig AC, McCarroll JR, Vanmeter CD: Knee dislocations with intact PCL. Orthop Rev 1992, 21(5):607-608. 610-601

16. Bratt HD, Newman AP: Complete dislocation of the knee without disruption of both cruciate ligaments. J Trauma 1993, 34(3):383-389.

17. Richter M, Bosch U, Wippermann B, Hofmann A, Krettek C: Comparison of surgical repair or reconstruction of the cruciate ligaments versus nonsurgical treatment in patients with traumatic knee dislocations. Am J Sports Med 2002, 30(5):718-727.

18. Schofer MD, Peterlein CD, Fuchs-Winkelmann S, Kortmann HR Arthroscopically-assisted combined anterior and posterior cruciate ligament reconstruction. Unfallchirurg 2008, 111(9):703-710.

19. Fanelli GC, Edson CJ: Arthroscopically assisted combined anterior and posterior cruciate ligament reconstruction in the multiple ligament injured knee: 2- to 10-year follow-up. Arthroscopy 2002, 18(7):703-714.

20. Harner CD, Waltrip RL, Bennett CH, Francis KA, Cole B, Irrgang JJ: Surgical management of knee dislocations. J Bone Joint Surg Am 2004, 86A(2):262-273

21. Liow RY, McNicholas MJ, Keating JF, Nutton RW: Ligament repair and reconstruction in traumatic dislocation of the knee. J Bone Joint Surg Br 2003, 85(6):845-851.

22. Mariani PP, Santoriello P, lannone S, Condello V, Adriani E: Comparison of surgical treatments for knee dislocation. Am J Knee Surg 1999, 12(4):214-221.

23. Noyes FR, Barber-Westin SD: Reconstruction of the anterior and posterior cruciate ligaments after knee dislocation. Use of early protected postoperative motion to decrease arthrofibrosis. Am J Sports Med 1997, 25(6):769-778.

24. Ohkoshi Y, Nagasaki S, Shibata N, Yamamoto K, Hashimoto T, Yamane S: Two-stage reconstruction with autografts for knee dislocations. Clin Orthop Relat Res 2002:169-175.

25. Oswald AS, Gachter A: Knee dislocation. Swiss Surg 1998:279-287.

26. Owens BD, Neault $M$, Benson E, Busconi BD: Primary repair of knee dislocations: results in 25 patients ( 28 knees) at a mean follow-up of four years. J Orthop Trauma 2007, 21(2):92-96.

27. Rios A, Villa A, Fahandezh $\mathrm{H}$, de Jose C, Vaquero J: Results after treatment of traumatic knee dislocations: a report of 26 cases. J Trauma 2003, 55(3):489-494.

28. Shelbourne KD, Haro MS, Gray T: Knee dislocation with lateral side injury: results of an en masse surgical repair technique of the lateral side. Am J Sports Med 2007, 35(7):1105-1116

29. Sisto DJ, Warren RF: Complete knee dislocation. A follow-up study of operative treatment. Clin Orthop Relat Res 1985:94-101.

30. Talbot M, Berry G, Fernandes J, Ranger P: Knee dislocations: experience at the Hopital du Sacre-Coeur de Montreal. Can J Surg 2004, 47(1):20-24.

31. Tzurbakis M, Diamantopoulos A, Xenakis T, Georgoulis A: Surgical treatment of multiple knee ligament injuries in 44 patients: 2-8 years follow-up results. Knee Surg Sports Traumatol Arthrosc 2006 14(8):739-749.
32. Wascher DC, Becker JR, Dexter JG, Blevins FT: Reconstruction of the anterior and posterior cruciate ligaments after knee dislocation. Results using fresh-frozen nonirradiated allografts. Am J Sports Med 1999, 27(2):189-196.

33. Wong CH, Tan JL, Chang HC, Khin LW, Low CO: Knee dislocations-a retrospective study comparing operative versus closed immobilization treatment outcomes. Knee Surg Sports Traumatol Arthrosc 2004 12(6):540-544

34. Yeh WL, Tu YK, Su JY, Hsu RW: Knee dislocation: treatment of highvelocity knee dislocation. J Trauma 1999, 46(4):693-701.

35. Mueller W: The Knee, Form, Function and Ligament Reconstruction. Berlin, Heidelberg: Springer-Verlag; 1983.

36. Hefti F, Muller W, Jakob RP, Staubli HU: Evaluation of knee ligament injuries with the IKDC form. Knee Surg Sports Traumatol Arthrosc 1993, 1(3-4):226-234

37. Irrgang JJ, Anderson AF, Boland AL, Harner CD, Neyret P, Richmond JC, Shelbourne KD: Responsiveness of the International Knee Documentation Committee Subjective Knee Form. Am J Sports Med 2006, 34(10):1567-1573

38. Anderson AF, Irrgang JJ, Kocher MS, Mann BJ, Harrast JJ: The International Knee Documentation Committee Subjective Knee Evaluation Form: normative data. Am J Sports Med 2006, 34(1):128-135.

39. Jenkinson C, Coulter A, Wright L: Short form 36 (SF36) health survey questionnaire: normative data for adults of working age. BMJ 1993, 306(6890):1437-1440.

40. Tegner Y, Lysholm J: Rating systems in the evaluation of knee ligament injuries. Clin Orthop Relat Res 1985:43-49.

41. Insall JN, Dorr LD, Scott RD, Scott WN: Rationale of the Knee Society clinical rating system. Clin Orthop Relat Res 1989:13-14.

42. Kellgren J, Lawrence J: Epidemiology of chronic rheumatism. Philadelphia, Pa: Davis: 1963

43. Cole BJ, Harner CD: The multiple ligament injured knee. Clin Sports Med 1999, 18(1):241-262

44. Shelbourne KD, Porter DA, Clingman JA, McCarroll JR, Rettig AC: Lowvelocity knee dislocation. Orthop Rev 1991, 20(11):995-1004.

45. Almekinders $L C$, Logan TC: Results following treatment of traumatic dislocations of the knee joint. Clin Orthop Relat Res 1992:203-207.

\section{Pre-publication history}

The pre-publication history for this paper can be accessed here: http://www.biomedcentral.com/1471-2474/11/102/prepub

\section{doi: 10.1186/1471-2474-11-102}

Cite this article as: Hirschmann et al., Clinical and radiological outcomes after management of traumatic knee dislocation by open single stage complete reconstruction/repair BMC Musculoskeletal Disorders 2010, 11:102 